\title{
A Transnational Field Approach to the Study of Labor Trafficking
}

\author{
Masja van Meeteren and Sanne Bannink
}

\section{Contents}

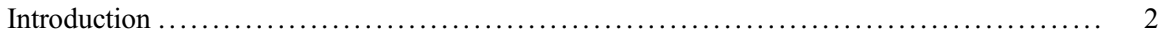

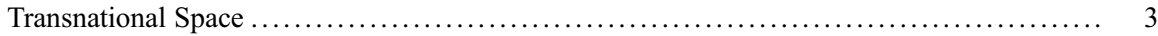

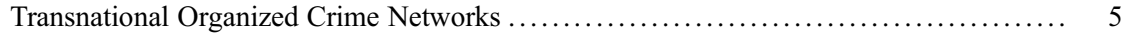

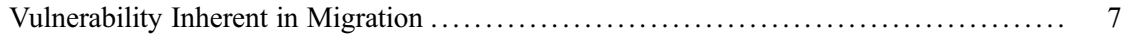

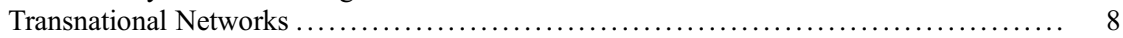

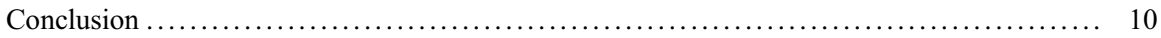

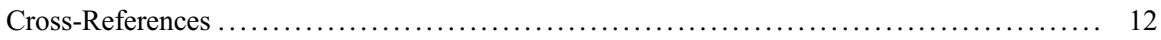

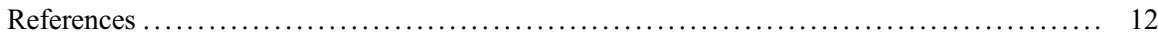

\begin{abstract}
Labor trafficking has increasingly become a subject of policy and research due to the rise in cross-border mobility and globalization. Whereas labor trafficking is generally approached through a criminal justice frame of transnational organized crime, in this contribution, a broader transnational social field approach is advocated. It is argued that this does more justice to the complex interconnectedness of contemporary reality and allows us to understand better how vulnerability on which human trafficking feeds is created. It is argued that a transnational field approach to labor trafficking allows us to understand better the different forms in which labor trafficking comes and the different ways in which transnational space plays a role in these. The Netherlands is used as an empirical illustration. It is illustrative of how transnational space plays a different role in three types of labor trafficking. For each type, three phases in the labor trafficking process are scrutinized: recruitment, transportation, and the phase of work. It is concluded that it would be helpful to approach labor trafficking not solely from a criminal justice perspective of transnational organized crime but to also include more
\end{abstract}

M. van Meeteren $(\bowtie) \cdot$ S. Bannink

Department of Criminology, Leiden University, Leiden, The Netherlands

e-mail: m.j.van.meeteren@law.leidenuniv.nl 
locally rooted approaches from a labor migration perspective, including a transnational field approach.

\section{Keywords}

Labor exploitation - Transnational organized crime $\cdot$ Transnational space $\cdot$ Transnational social field $\cdot$ Transnational crime $\cdot$ Human trafficking $\cdot$ Labor migration

\section{Introduction}

As globalization continues to facilitate many legal processes, criminal actors may also exploit globalization for illegitimate purposes. With the advent of globalization, transnational crime has been on the rise, usually framing it as an adverse effect of globalization (Marmo and Chazal 2016). The first evidence of the concept "transnational crime" being used is in the 1970s when the United Nations (UN) started to use the term to refer to the increase in criminal activities that transcend national jurisdictions. In 1995, transnational crime was defined as "offences whose inception, prevention and/or direct or indirect effects involved more than one country." UN Doc. A.CONF. 169/15/Add.1 (1995, p4), with the United Nations distinguishing between 18 types of transnational crimes, human trafficking being one of them. The label transnational crime is hence not only used to provide a definition for types of crimes that traverse borders but has since then also been rather specific, referring to particular types of crime, including human trafficking (Marmo and Chazal 2016), with the result that, in policy terms, human trafficking has been framed as a form of transnational crime.

Although transnational crime entered the discourse of criminology in the 1970s, scholars only started to seriously research it in the 1990s (Felsen and Kalaitzidis 2005). The end of the Cold War and the emergence from communism of new states in Eastern Europe gave way to concerns over nation-states' vulnerability to transnational criminal activity. The first scholarly definition of transnational crime was offered by Bossard (1990: 5, cited in Felsen and Kalaitzidis 2005) as "an activity that is considered a criminal offense by at least two countries."

At the same time, there is little consensus over the definition of transnational crime. Transnational crimes are different from international crimes, which involve crimes against humanity, such as genocide, and may or may not involve multiple countries. International crimes often have a political or religious motive, whereas transnational crimes are characterized by motives of personal gain and profit (Albanese 2012). Many scholars highlight the organized nature and equate transnational crime with transnational organized crime. Albanese (2012: 3), for example, asserts that "transnational crime is a form of organized crime given its multinational aims and the extent of organization required for success." "Transnational organized crime" is also the term mostly used by the United Nations.

Since 2000, the punishment of human trafficking has been regulated internationally and laid down in the Palermo Protocol of the United Nations. The Palermo 
Protocol is part of the United Nations Convention Against Transnational Organized Crime (UNTOC). The Protocol represented an enormous step forward in international cooperation against transnational crime. Simultaneously, it received criticism as it used the term "transnational organized crime" instead of "transnational crime." This potentially limits the frame in approaching transnational crime by practitioners and researchers (Marmo and Chazal 2016).

Furthermore, whereas human trafficking used to concern trafficking of women for sexual exploitation mainly, with the Palermo Protocol, the definition of human trafficking was widened to include other kinds of exploitation. This widening arose from the internationally growing unrest of what is usually referred to as "modern slavery." As a result, the concept of human trafficking now includes a multitude of situations that were not previously seen as human trafficking, including labor exploitation. Furthermore, this multitude of forms of exploitation has been criminalized as part of the UNTOC. As scholars have pointed out, not all human trafficking cases necessarily involve organized crime, and this is probably even less so in cases of labor trafficking.

Moreover, transnationality is not part of the constituent elements of the offense (cross-ref to Siller and Van Doore). Not all cases of human trafficking are therefore necessarily transnational, and this is, perhaps, also even less so for cases of labor trafficking. The fact that they are criminalized under that heading does not necessarily mean that transnational space plays an essential role in these "new" phenomena.

This contribution explores how transnational space plays a role in one of these relatively "new" forms of human trafficking: labor trafficking. By doing so, labor trafficking in the Netherlands is used as an illustration. The Protocol's definition was incorporated by the Dutch legislature in 2005 into article $273 \mathrm{f}$ of the Criminal Code and is a literal translation of the Protocol's text.

\section{Transnational Space}

As the role of transnational space in labor trafficking is explored, it is essential to explain how transnational space is defined and discuss the literature on which it builds. This section aims to outline this theoretical framework. A theoretical model that is often used to explain transnational human trafficking is the economic push and pull model. The idea is that potential victims who live in "source countries" or "sending countries" are pushed toward "destination countries" because of bad socioeconomic conditions in the source countries. The "destination countries," on the other hand, pull victims with luring economic opportunities and a relatively high standard of living. "Transit countries" are those countries that encounter trafficking situations because of its geographical position and are used for transportation routes between source and destination countries. Following this model, the Netherlands is usually seen as a typical "destination country" in human trafficking.

However, such a view of transnational space involved in human trafficking, that classifies countries in source, destination or transit countries, is increasingly challenged 
for being overly simplistic and not doing justice to the more complex reality of trafficking situations (Kragten-Heerdink et al. 2018). After all, even though the word "trafficking" seems to imply movement, border crossing is not a requirement under the definition of the UN Palermo Protocol. Others, therefore, differentiate between "country of recruitment" and "country of exploitation" and state that trafficking situations can also occur in the country of recruitment. Kragten-Heerdink et al. (2018: 5-6) introduced a model that identifies four different routes of human trafficking based on where the actions of the process of human trafficking take place. Also, they analyzed 768 human trafficking cases identified by the Dutch Public Prosecution Service (2008-2012) and categorized each case according to this model. Unfortunately for this chapter, they do not single out cases of labor exploitation, but they did differentiate between sexual and nonsexual exploitation and identified 104 cases of nonsexual exploitation. As this work represents a first step in improving the understanding of the role of transnational space in labor trafficking cases, the results are briefly outlined below.

The first route is referred to as "arrived cross-border trafficking." In such cases, the Netherlands is involved as the country of exploitation and victims are recruited abroad. This concerned 73 nonsexual cases. The second route concerns "departed cross-border trafficking." The Netherlands is involved as a country of recruitment in such cases. This concerned four cases of nonsexual exploitation. In all these cases, recruitment took place in the Netherlands, but the exploitation occurred in a neighboring country. The authors, therefore, label these cases "departed near-domestic trafficking" instead of "departed cross-border trafficking." The third route is referred to as "domestic trafficking." In such cases, the Netherlands is involved both as the country of recruitment and the country of exploitation. No cross-border movement takes place in this trafficking route, and it concerned 22 cases of nonsexual trafficking. The fourth route pertains to cases of "traversed cross-border trafficking." With this human trafficking route, the Netherlands is only involved as a country of transit. Kragten-Heerdink et al. (2018) did not identify any nonsexual trafficking cases of this kind.

This model represents a significant improvement to the traditional push and pull model, recognizing that one country is not solely a "destination country" but that it can be involved in multiple actions in the process of human trafficking and that the actions that occur on its soil may differ in each trafficking case. However, doing so, it conceives of transnational space mainly as a geographical space in which people can move or not move. It asks the question within the borders of which nation-state human trafficking processes take place. Such a nation-state view of societies has increasingly received critique from scholars of migration studies (Levitt and GlickSchiller 2004). In this contribution, a broader definition of transnational space is used, conceptualizing transnational space as a social space. Borrowing from transnational migration studies, a social field approach to the study of transnational labor exploitation is explored. This provides the opportunity to capture better the complex interconnectedness of contemporary reality than a nation-state container view of societies does.

This contribution aligns with distinguished scholars of transnational migration studies and defines a social field as "a set of multiple interlocking networks of social 
relationships through which ideas, practices and resources are unequally exchanged, organized and transformed" (Levitt and Glick-Schiller 2004: 1009). This conceptualization of the social field finds its roots in the work of Bourdieu. Bourdieu used the concept of social field to draw attention to how social relationships are structured by power. A social field is comprised of people who struggle for social position within the field. Its boundaries are fluid, and national boundaries are not necessarily contiguous with the boundaries of social fields. National social fields are those that stay within national boundaries, while transnational social fields connect actors through direct and indirect relations across borders (Levitt and Glick-Schiller 2004).

The concept of transnational social fields represents a useful tool for conceptualizing the social relations and interactions linking those involved in labor trafficking. It provides the opportunity to see the actions involved in the process of labor trafficking not only of those who move but also of those who do not move but are part of transnational social fields. The maintenance of meaningful social relationships across borders plays an important role and are essential to consider when examining labor trafficking.

Furthermore, when those involved in human trafficking are socially linked to multiple settings, they deal with the regulatory powers and the hegemonic culture of more than one nation-state. Moreover, it is not only the power of the state as expressed through laws and the actions of its criminal justice apparatus; power in transnational social fields pervades and permeates all social relations (Foucault 1980). People in transnational social fields experience multiple loci and layers of power and can strategically take advantage of the way power is structured in their advantage. Vice versa, the way transnational social fields are structured makes some people relatively powerless. Also, navigating a social field is "learned" through experience in "playing" it, and this experience makes it possible to obtain a better position.

In exploring how transnational space plays a role in labor trafficking, this contribution conceives of transnational space as a transnational social field. It should have become clear that in doing so, it poses a fundamentally different question than the question of where actions in the human trafficking process are located. It is explored how transnational space plays a role by discussing the different roles it plays in three types of labor trafficking, which are discussed next. For each type, three phases in the labor trafficking process are examined - (1) the recruitment, (2) the transportation, and (3) the phase of work - while recognizing that labor trafficking does not necessarily need to comprise all three phases.

\section{Transnational Organized Crime Networks}

The first way in which transnational space can play a role is the most obvious one that is well known in the literature. It concerns organized crime networks that operate across transnational space. The crime network controls all three phases of the human trafficking process from recruitment to transportation to the work situation. Recruitment generally takes place in a different country than the country where the actual 
work takes place, and the recruiters take advantage of the wage differentials between these countries.

In many cases, victims do not have a substantial economic position, and they would like to generate a better income for themselves or their families. They do not usually know much about rules and regulations concerning working abroad, which makes them vulnerable to recruitment under pretenses. Traffickers can use the victims' dreams of making more money to provide for their family. False anecdotes are told, portraying a false truth of the available work. This is often reinforced with stories victims learn about through word of mouth, or that they see on social media. The criminal organization generally initiates the recruitment process and has the purpose of employing the victim in the Netherlands under exploitative circumstances while benefitting financially from this process.

After recruitment, the criminal network also arranges for transportation to the country in which the victims will be forced to work. If needed, victims will be smuggled across borders, or the traffickers arrange for false identification. To "control" their victims, traffickers create dependency, for example, through debt bondage related to the transportation costs. When someone owes a debt to someone, this person is in the difficult position of having to repay this debt. This debt bondage or the use of "fees" is a common tool used by transnational organized crime networks. Victims have to pay for several services, "service fees," creating a debt to their traffickers (Europol 2016). Victims are highly dependent on the criminal network as they control everything. The traffickers use the vulnerability and the desperation of the victims to force them to work to repay the so-called debts that have been created. When the trafficker has earned enough money, and the victim supposedly has paid off its debt, it is possible in some cases for the victims to leave (Europol 2016). The victims have not earned any money and return home ashamed and empty-handed.

This criminal network is based on criminal collaboration, and there is a certain degree of professionalism. There are transnational networks present in different countries recruiting, transporting, and employing victims all over Europe. These types of networks adapt quickly to different circumstances and can vary in size (Europol 2016; Leman and Janssens 2015). They are often footloose networks with a clearly defined distribution in jobs (Bruckert et al. 2002). In many cases, the networks make use of freelance recruiters and chauffeurs. These freelancers can work for different networks (Farrell et al. 2010; Shelley 2010), and social media plays an essential role in establishing this. Traffickers advertise via these channels to recruit freelancers and to provide information. By using social media, these networks can adapt quickly to different circumstances (Europol 2016). The networks can vary in size, and victims can also be exchanged from one trafficker to another (Europol 2016; Shelley 2010).

In such cases, where criminal networks operate across transnational space, all three phases of the trafficking process are controlled by them. The network occupies essential positions in the transnational social field and has learned to navigate the field well. In doing so, it can control the whole process of labor trafficking from recruitment to transportation to the work situation. Its victims, on the other hand, 
have limited to no experience in the field, often not well aware of the forces that structure it. The traffickers strategically use the power differentials in the transnational social field to their advantage. Labor trafficking, in this case, is a form of transnational organized crime which can be considered the modern extension of organized crime in the globalized era (Albanese 2012). The transnational criminal network is often mentioned in the international literature on human trafficking, yet it is not a form of labor trafficking that is seen very often in the Dutch context (Van Meeteren and Van der Leun 2018).

\section{Vulnerability Inherent in Migration}

In the previous category, recruitment and transportation were facilitated across transnational space by third parties. The second category is characterized by the independence of the victims in the first two phases: recruitment and travel. They can navigate transnational space on their own without needing assistance from third parties who possibly take advantage of them. However, the employer can take advantage of specific vulnerabilities that find root in the migratory background of the victims. Victims, for example, depend on their employer because they do not speak Dutch and are unfamiliar with Dutch employment rules. They do not have a good social network in the Netherlands to turn to for help. Additionally, the victim can also be in a vulnerable situation as she/he may have borrowed money to finance the migration project.

Dutch professionals who operate in the field of labor exploitation see that this form of labor exploitation is more common among origin country groups that have long established migration patterns. They hypothesize that a more extended stay has an emancipating effect. For example, Polish labor migrants used to migrate to the Netherlands with a recruitment agency or a middleman. However, over time they have learned what the best ways are to go, so they go independently.

The rise of the Internet and the use of social media are vital in understanding how this category can arrange for the migratory trip independently. Nowadays it is easy to find work online because it facilitates immediate contact between employer and employee. Different types of websites, ones that are more resume based and ones that are more vacancy based, exist that directly mediate transnational labor supply and demand. Social media and technology contribute to this; even in rural areas, people have cell phones which makes it easy to get in contact with future employers but also with future exploitative employers. It is also a place where prospective migrants can find each other and arrange for collaborative transportation or find bus tickets.

The victims in this category are better positioned in the transnational field through the informal institutions that have emerged as a result of long-lasting labor migration. They, therefore, do not have to depend on others to help navigate them, but they can operate by themselves. It is not transnational space that plays a role in their exploitation but their background as international migrants, as it creates and sustains vulnerabilities. It is not their position in a transnational social field that makes them 
vulnerable but their position in the national social field of the Netherlands that does. Employers are better positioned in Dutch society, and they can make use of migrants who are less well-positioned. Employers may try to sustain that by limiting workers' access to information and social contacts in the Netherlands. In many other cases, employers knowingly use their employees' absence of a legal resident status.

This category includes victims that were not recruited but arrived on their initiative. Also, it includes victims who are recruited in the Netherlands. The latter, for example, happens a lot in places where migrant workers share a house in a bungalow park or at a campsite. Places, where many people from the same country of origin live together, are active recruitment sites. Such places tend to be occupied by migrant workers. Those who are temporarily out of work, not happy with their current work conditions, or not satisfied with the payment they currently receive are easy targets to be lured into a job under pretenses (Willemsen 2010). In such cases, it is not vulnerabilities in transnational space that play a role but vulnerabilities related to their position as international migrants, unfamiliar with the rules and rights of the national context in which they work.

\section{Transnational Networks}

The third category differs from the previous category in that victims do depend on others to navigate transnational space. Moreover, it is different from the first category as it is not characterized by an all-in package but by a chain of different actors who provide for a part of the trafficking process and who operate more or less independently. The difference between this category and the first one is the lack of a criminal network that controls all the elements of the human trafficking process. Also, not necessarily all actors in the chain are actively involved in the trafficking process or aware of their facilitation. This category can be subdivided into two subcategories, A and B. In case of A, the actors involved in recruitment and travel are professionals, and in case of B the actors involved in recruitment and travel are informal social networks.

In the case of A, the actors involved in the recruitment and transportation phase are generally professional middlemen, recruitment agencies, or smugglers. Professional intermediaries can work for a recruitment agency or work as an independent contractor. They can recruit employees via advertisements, on the streets, or via acquaintances. In other cases, professional, legitimate recruitment agencies operate as a link between the employer and employee. Such recruitment agencies often attempt to act in the employees' best interest and unconsciously facilitate exploitation. These agencies make travel arrangements for employees and/or mediate in seeking employment and are usually characterized by legitimate business structures (Leman and Janssens 2015; Levenkron 2007).

When the journey or part of the journey involves illegal border crossings, victims often make use of human smuggling agents. Victims have to pay for these services, and in many cases, the costs involved are quite high. In the market of human smuggling, legitimate business people operate that charge a fee for their services 
but also cheat by raising the costs along the way or rob the people they transfer across borders. In some cases, human smuggling networks and human trafficking networks are intertwined in criminal networks; in such cases, they fall under the first category. However, in many cases, they unconsciously facilitate a human trafficking process.

Regardless of the type of professionals that services are bought from, victims pay large sums of money for the services that go-betweens, recruitment agencies, or human smugglers provide. In some cases, victims take out loans in order to pay for these services. Victims will have to work in order to earn back the money that they invested in their migratory projects, which makes them vulnerable. However, unlike in the first category, where dependency is created vis-à-vis the criminal network, it is not a criminal network that controls them but the situation they are in that makes them vulnerable, having accumulated debt with different actors in the transnational field.

While the professionals operate in a transnational social field they know well, victims have no or hardly any knowledge of how to navigate it. However, although the professionals strategically use this advantage to make large sums of money off international migrants, to be qualified as traffickers, they would knowingly have to do this to get victims in a forced labor situation. The latter is not always the case, let alone challenging to prove.

In the case of $\mathrm{B}$, where the actors involved in recruitment and travel are informal social networks, it is also not a transnational crime network that controls the victims' situation but the situation they are in that makes them entrapped. Recruitment and transportation for this subcategory are arranged by informal social networks that are not criminal. These social networks are comprised of friends, acquaintances, and family members. Like in the other subcategory, some people in the informal social network may benefit from making their arrangements regarding recruitment and transportation. However, with informal social networks, this is often not the case. The services that friends or family members provide are usually not part of a clear strategy or long-term plan but rather a single event. Employers, for example, ask their employees if they know someone who also wants to work for them. Some cases are known in which victims are recruited through their social networks by people who are themselves in an exploitative situation (Bogaerts et al. 2010). These persons become sort of intermediaries (Postma and Van Wijk 2012). It is unknown mainly why victims willingly recruit new victims for their employers, but there is likely to be some form of gain in it for them, financial or otherwise, for example, a shared emotional burden.

Probably in most other cases in the Netherlands, informal transnational social networks do not consciously lure migrants into trafficking situations, but they unconsciously contribute to it. In the migration literature, the positive outcome of transnational social networks regarding increased social mobility is usually emphasized. However, scholars increasingly also point at the adverse effects of social networks (Cranford 2005). It is often argued that migrants who work on the margins of society try to make ends meet by taking advantage of newcomers or those who occupy even lower positions on the social hierarchy (Mahler 1995). 
With subcategory $3 \mathrm{~A}$ and $3 \mathrm{~B}$, transnational space plays a similar role in that there are others - professionals in $3 \mathrm{~A}$ and informal social networks in $3 \mathrm{~B}$ - that assist victims in navigating the transnational social field with recruitment and transportation. While doing so, they take advantage of them or at least ask a price for their services, possibly creating a situation of dependency. This results in a situation that is difficult to get out of for victims. Transnational space plays a role in that it works to the disadvantage of victims in recruitment and transportation. Due to the debts and obligations these two phases create, employers may also use those vulnerabilities created in these two phases in the third phase of actual work. This is in addition to the vulnerabilities that victims already have as international migrants in a new country.

Every actor in the transnational or national social field takes advantage of the victims in their way as they are better positioned than the victim, though not necessarily with the intent of creating a labor trafficking situation. As such, it is the situation victims are in that controls them, but there is not a criminal network that has consciously created this situation. Every party has strategically taken advantage of the victims as they occupy a stronger position in the transnational social field (mediators) or the national social field (employer). Together they have created a situation in which victims have become entrapped.

\begin{tabular}{l|l|l|l}
\hline & $\begin{array}{l}\text { Transnational } \\
\text { organized } \\
\text { crime } \\
\text { networks }\end{array}$ & $\begin{array}{l}\text { Vulnerabilities } \\
\text { inherent in } \\
\text { migration }\end{array}$ & Transnational networks \\
\hline Recruitment & $\begin{array}{l}\text { Crime network } \\
\text { has a power } \\
\text { advantage }\end{array}$ & $\begin{array}{l}\text { No recruitment, } \\
\text { individual agency }\end{array}$ & $\begin{array}{l}\text { Professionals or informal social } \\
\text { networks who have the power } \\
\text { advantage }\end{array}$ \\
\hline Transportation & $\begin{array}{l}\text { Crime network } \\
\text { has a power } \\
\text { advantage }\end{array}$ & $\begin{array}{l}\text { Victims have } \\
\text { enough power to } \\
\text { arrange themselves }\end{array}$ & $\begin{array}{l}\text { Professionals or informal social } \\
\text { networks who have the power } \\
\text { advantage }\end{array}$ \\
\hline Work & $\begin{array}{l}\text { Forced labor } \\
\text { arranged by a } \\
\text { crime network }\end{array}$ & $\begin{array}{l}\text { Forced labor result } \\
\text { of vulnerability } \\
\text { inherent in } \\
\text { migration }\end{array}$ & $\begin{array}{l}\text { Forced labor result of vulnerability } \\
\text { inherent in migration and lack of } \\
\text { power in transnational space }\end{array}$ \\
\hline Trafficking & All-in package & $\begin{array}{l}\text { The result of } \\
\text { vulnerability } \\
\text { inherent in } \\
\text { migration }\end{array}$ & $\begin{array}{l}\text { The result of a situation in which } \\
\text { they have become entrapped }\end{array}$ \\
\hline
\end{tabular}

\section{Conclusion}

According to Albanese (2012: 1), transnational crime is "a law violation that involved more than one country in its planning, execution or impact." He further asserts that "their multinational nature and cross-border impact distinguish transnational crimes." It has been illustrated that not all cases of labor trafficking merit the 
label of "transnational crime," regardless of definition. The downside of such a view on transnational crime is that it takes nation-states and their criminal justice systems as a focus point. A transnational field approach, on the other hand, takes how the crime manifests itself as a starting point. In other words, it does not take the fact that more than one country is involved in its combat as a starting point, but it takes the social phenomenon itself as a focus. Doing so, adopting a (transnational) social field approach to the study of labor exploitation allows us to understand better how vulnerability is created in a globalized world. It provides us with the opportunity to see how traffickers operate in markets that are "inherently tied to social inequalities associated with the negative impact of globalization" (Marmo and Chazal 2016: 94).

The UN has done an excellent job in calling for international attention for human trafficking with the 2000 Palermo Protocol. Perhaps by framing the issue as a matter of transnational organized crime, it has managed to get the massive attention that it currently gets and would otherwise not have been able to receive. At the same time, the arguments presented here demonstrate that the Protocol is focused on combatting labor trafficking cases of the first type. By calling attention to "transnational organized crime," it discursively leaves out the combat of the other types. Moreover, it illustrates that definitions of crime "are often presented as neutral and value-free categories" which they are not (Marmo and Chazal 2016: 13). In the case of human trafficking, it masks politics that are not concerned about human rights but rather is imposed by the necessity to combat border security and organized crime (Marmo and Chazal 2016).

In line with the underlying politics, relationship with the traffickers and victim conditions was labeled as a process of agency stripping, where "in the first few years of the Protocol's life, the victim conditions and relationship with the traffickers have been described, with the victim being physical, psychologically and possibly sexually abused" (Marmo and Chazal 2016: 99). By now it is known that the reality is far more fragmented and that many more subtle forms of force are used. The Protocol has artificially separated victims and offenders as two separate and different categories. However, over the years, UN reports indicate that many offenders were victims themselves, in what is referred to as a "cycle of abuse" when the status of the victim overlaps with that of the offender (Marmo and Chazal 2016: 99).

With such a complex and multifaceted phenomenon as labor trafficking, it was not the purpose of this chapter to argue whether or not labor trafficking is in its essence transnational or not. Instead, the aim was to show how a transnational field approach to labor trafficking allows us to understand better the different forms in which labor trafficking comes and the different ways in which transnational space plays a role in structuring power relations within the field. This better allows us to understand the different ways in which transnationalism may play a role in this type of crime. Besides, it allows us to see the cases in which it does not play a role or at least not in the way that is generally thought of when discussing transnational organized crime. Furthermore, there are also cases where victims nor perpetrators have a migratory background, and there is no movement across borders. These were not discussed here as the role of transnational space could a priori be dismissed. There have, for example, been cases where native Dutch residents with mental 
disability were forced to work in exploitative circumstances. It stands to reason that the framing of their harm as transnational organized crime does not do justice to their situation. All in all, not only are manifestations of labor trafficking not always transnational when they are, transnational space can play a variety of roles, with transnational organized crime being one out of several manifestations.

Adopting a transnational field approach will equally demonstrate solutions to the problem. It would be helpful to approach labor trafficking not solely from the perspective of transnational criminal justice but also to include more locally rooted approaches from a labor migration perspective. With increasing globalization and the rise of people who know how to navigate the Internet, potential labor migrants increasingly know how to arrange for their migration themselves. So it is likely that this group is only going to grow larger. This means that research on strengthening the position of labor migrants and facilitating integration also has the potential to prevent future exploitation and therefore deserves more attention in policy-making.

\section{Cross-References}

Establishing the Constituent Elements of Trafficking in Persons Conceptualizing "Transnationality" and "Involvement by an Organized Criminal Group"

- Exploitation of Migrant Workers: A Multi-legal Approach of Labor Exploitation

- Human Trafficking in Supply Chains and the Way Forward

- Individual Criminal Responsibility Beyond the State: Human Trafficking as Both a Transnational and an International Crime

- Is It Time for a New United Nations Treaty on Human Trafficking

\section{References}

Albanese JS (2012) Deciphering the linkages between organized crime and transnational crime. Journal of International Affairs 66(1):1-17.

Bogaerts A, Plooij P, Zoetekouw R (2010) De bestrijding van arbeidsuitbuiting. Justitiële Verkenningen 36(7):68.

Bossard A (1990) Transnational crime and criminal law. Chicago, IL: Office of International Criminal Justice.

Bruckert C, Parent C, Police R C M (2002) Trafficking in human beings and organized crime: A literature review. Research and Evaluation Branch, Community, Contract and Aboriginal Policing Services Directorate, Royal Canadian Mounted Police. http://nswp.gn.apc.org/sites/ nswp.org/files/RCMP-TRAFFICK.pdf Accessed on 15 Jan 2018.

Cranford CJ (2005) Networks of exploitation: Immigrant labor and the restructuring of the Los Angeles janitorial industry. Social problems 52(3):379-397.

Europol (2016). Situation report: Trafficking in human beings in the EU. https://ec.europa.eu/anti trafficking/sites/antitrafficking/files/situational_report_trafficking_in_human_beings_europol.pdf Accessed on 15 Feb 2016

Farrell A, McDevitt J, Fahy S (2010) Where are all the victims? Criminology \& Public Policy 9 (2):201-233

Felsen D, Kalaitzidis A (2005) A historical overview of transnational crime. In: Reichel P (ed) Handbook of transnational crime \& justice. SAGE Publications, Thousand Oaks, pp 3-19 
Foucault M (1980) Power/Knowledge: Selected Interviews and Other Writings, 1972-1977. Pantheon, New York

Kragten-Heerdink SLJ, Dettmeijer-Vermeulen CE, Korf DJ (2018) More Than Just "Pushing and Pulling": Conceptualizing Identified Human Trafficking in the Netherlands. Crime \& Delinquency, 64(13):1765-1789. https://doi.org/10.1177/0011128717728503

Leman J, Janssens S (2015) Human trafficking and migrant smuggling in Southeast Europe and Russia: learning criminal entrepreneurship and traditional culture. Transnational crime, crime control and security.

Levenkron N (2007) Deported and Dispossessed: Human Trafficking and the State of Israel: Between Economic Struggle and Systemic Dispossession. Hotline for Migrant Workers, Tel Aviv

Levitt P, Glick-Schiller N (2004) Conceptualizing Simultaneity: A Transnational Social Field Perspective on Society. International Migration Review 38(3):1002-1039

Mahler, S. (1995) American dreaming: immigrant life on the margins. Princeton University Press

Marmo M, Chazal N (2016) Transnational Crime \& Criminal Justice. Sage, London

Postma D, Wijk J V (2012) Op het land in plaats van achter het raam; aard en omvang van arbeidsuitbuiting in Nederland. http://dare.ubvu.vu.nl/handle/1871/49403 Accessed on $12 \mathrm{Apr}$ 2016.

Shelley L (2010) Human trafficking: a global perspective. Cambridge University Press, Cambridge.

UN doc.A.conf. 169/15/add1 (1995) retrieved from: https://www.unodc.org/documents/congress/ Previous_Congresses/9th_Congress_1995/017_ACONF.169.15.ADD.1_Interim_Report_ Strengthening_the_Rule_of_Law.pdf

Van Meeteren M, Van der Leun J (2018) Daders van arbeidsuitbuiting. Over de vermeende rol van de georganiseerde misdaad, Proces. Tijdschrift voor strafrechtspleging 97(2):130-146.

Willemsen E (2010) Uitbuiting in andere sectoren dan de seksindustrie (report). BlinN/HumanitasOxfam Novib, Amsterdam 